\title{
O regime enunciativo na prova de redação do ENEM
}

\section{The enunciative regime in the ENEM'S writing test}

\author{
Luana Aparecida Matos Leal Fernandes ${ }^{1}$ \\ Carmen Lucia Hernandes Agustini ${ }^{2}$
}

\begin{abstract}
Recebido em: 19/10/2020
Aprovado em: 22/12/2020

Publicado em: 30/07/2021
\end{abstract}

RESUMO: Neste artigo, problematizamos o funcionamento da argumentação na prova de redação do ENEM. Para tanto, analisamos, sob a perspectiva teórica de Emile Benveniste, a proposta de redação do ENEM 2016, bem como uma produção textual escrita. Assumimos que a argumentação na redação do ENEM compreende, para além da defesa de um ponto de vista, por meio do manejo da língua escrita e da mobilização de certo repertório, uma elaboração textual em função do regime enunciativo instituído na e pela proposta de redação da prova. Esse regime está relacionado aos textos motivadores que determinam a orientação argumentativa do texto a ser produzido. $\mathrm{Na}$ análise, mostramos que a argumentação nessa prova está marcada por uma injunção coercitiva que imprime diretrizes a serem observadas no texto produzido, a fim de que este seja bem avaliado. Assim, argumentar na prova de redação do ENEM não é "defender seu ponto de vista", mas o ponto de vista implicado no regime enunciativo estabelecido na e pela prova.

Palavras-chave: Escrita; Regime enunciativo; Redação ENEM.

ABSTRACT: In this article, we problematize the functioning of the argument in the ENEM essay test. To this end, we analyzed, from the theoretical perspective of Emile Benveniste, the proposal for the writing of ENEM 2016, as well as a written textual production. We assume that the argumentation in the ENEM writing comprises, in addition to defending a point of view, through the management of the written language and the mobilization of a certain repertoire, a textual elaboration in function of the enunciative regime instituted in and by the proposal of the writing of the test. This regime is related to the motivating texts that determine the argumentative orientation of the text to be produced. In the analysis, we show that the argument in this exam is marked by a coercive injunction that prints guidelines to be observed in the text produced, so that it is well evaluated. Thus, arguing in the ENEM's essay test is not "defending its point of view", but the point of view implied in the enunciative regime established in and by the exam.

Keywords: Writing; Enunciative regime; ENEM.

1. Doutora em Estudos Linguísticos - UFU. Professora de Língua Portuguesa no Instituto Federal do Norte de Minas Gerais - IFNMG/Campus Salinas. ORCID: 0000-0002-7654-2813. E-mail: luamatosleal@gmail.com 2. Doutora em Linguística pela Unicamp e docente no Programa de Pós-Graduação em Estudos Linguísticos da Universidade Federal de Uberlândia/UFU. ORCID: 0000-0001-5504-3911. E-mail: carmen.agustini@gmail.com. 
FERNANDES, L.A.M.L.; AGUSTINI, C.L.H.

\section{INTRODUÇÃO}

A modernidade e seus aspectos neoliberais têm influenciado diretamente 0 trabalho com a produção textual escrita nas escolas e o ensino dessa atividade vem se desenvolvendo com a finalidade de atender a uma demanda institucional específica de cumprimento de programas e preparação para processos seletivos e avaliações externas. Assim, situações que envolvem tanto o ato de escrever quanto o de ensinar acabam por atender a uma série de modelos, o que acaba por estabelecer uma prática de escrita escolar de cabresto, oportunizando a emergência de certo treinamento para a execução de uma tarefa específica.

Além desse fato, a fragmentação das disciplinas nas escolas, assim como a criação da disciplina de Redação, perpetua o ideário de que a escrita deve atender a um decalque dos modelos para vestibulares e concursos, e, mais especificamente, para a prova de redação do Exame Nacional do Ensino Médio (doravante ENEM). Essas colocações colaboram para que o ensino e o aprendizado da escrita mantenham seu caráter unicamente institucional.

Assim, ao considerarmos o trabalho com a escrita nas escolas, chama-nos atenção o fato de que a produção textual escrita está sendo orientada para um fim determinado, qual seja a correção/avaliação, seguindo critérios preestabelecidos, e isso faz com que o trabalho em sala de aula preze por um modelo textual, a partir do treino e do trabalho com estratégias e dicas a fim de se promover uma preparação para as provas de seleção.

Nesse sentido, olhamos para a prova de redação do ENEM e analisamos o modelo de escrita cobrado nesse exame, a partir da proposta de produção de um texto dissertativo-argumentativo. Mais especificamente, estudamos 0 funcionamento enunciativo da argumentação nessa produção textual escrita e o modo como o candidato/autor procura atender à demanda do exame para alcançar uma boa nota. Nessa perspectiva, a discussão que fazemos neste artigo pauta-se em dois objetivos específicos: a) explicitar a relação entre a argumentação produzida na redação do ENEM e o regime enunciativo instituído na e pela proposta de redação e b) mostrar a "influência" dos textos motivadores na construção da argumentação na redação do ENEM.

\section{Considerações sobre escrita escolar no ensino médio}

No Ensino Médio, o domínio da Língua Portuguesa e das habilidades de escrita é considerado fundamental e, por esse motivo, os Parâmetros Curriculares Nacionais do Ensino Médio (PCNEM) destacam que esse ensino não pode focar a língua divorciada do 
FERNANDES, L.A.M.L.; AGUSTINI, C.L.H.

meio social vivido pelo aluno, já que "sendo ela dialógica como princípio, não há como separá-la de sua própria natureza, mesmo em situação escolar" (PCNEM, 2000, p. 17).

Em se tratando da produção textual escrita na escola, é necessário considerá-la também como uma forma de materialização linguística, que permite ao homem se relacionar com o seu meio social e confrontar pontos de vista, ampliando o potencial crítico, por meio da linguagem. Ainda nessa perspectiva, os PCN+ complementam a discussão e afirmam que "muito mais do que um conjunto de orações ou frases, os textos estão impregnados de visões de mundo proporcionadas pela cultura e resultam, necessariamente, das escolhas e combinações feitas no complexo universo que é uma língua" (PCN+, s/d, p. 58). Nesse sentido, os documentos oficiais sobre o ensino de escrita em Língua Portuguesa no Ensino Médio enfatizam que a escrita pode e deve possibilitar aos alunos a produção de textos escritos em determinadas condições e suas coerções sociopolíticas.

Seguindo a proposta dos PCNEM, o trabalho com a produção textual no Ensino Médio tende a focar o ensino de gêneros textuais. Seja nos projetos político-pedagógicos das escolas, seja nas matrizes de referência dos documentos que organizam o currículo escolar e nos próprios livros didáticos, quando se trata de "produção textual escrita1", o que verificamos é uma perspectiva de escrita utilitária, em decorrência da abordagem de língua como língua em ação, língua em uso, como interação e atuação social. Assim, simulando uma experiência de linguagem, o ensino de escrita concentra-se no ensino de gêneros textuais, considerando a necessidade de escrever para atender a um fim, em conformidade ao meio sociocomunicativo.

É nessa perspectiva que, considerando a divisão tipológica tradicional de produção de textos, as aulas de Língua Portuguesa/Redação, no terceiro ano do ensino médio, priorizam o trabalho com a tipologia textual dissertativo-argumentativa, mais especificamente, com o texto no modelo da redação escolar. A produção dessa redação escolar clássica segue algumas condições de realização: a partir de um tema, discutido ou sugerido, os alunos devem escrever de acordo com um modelo prévio, seguindo uma estrutura composicional e um estilo de linguagem adequado à tipologia. Esse processo de escrita tem um propósito legítimo, qual seja a correção pelo professor, o que gera uma relação ritualizada entre professor e aluno. Nesse sentido, a redação escolar torna-se um gênero que circula na escola, a fim de cumprir objetivos pedagógicos, bem como para preparação para as avaliações externas e os processos seletivos. E, fora da escola,

\footnotetext{
1 Trata-se da divisão apresentada por grande parte dos livros didáticos de Língua Portuguesa, que organizam o ensino em partes específicas para o trabalho com Gramática, Literatura e Produção Textual.
} 
FERNANDES, L.A.M.L.; AGUSTINI, C.L.H.

funciona como um meio de avaliar a escrita e selecionar candidatos ao ensino superior e/ou ao mercado de trabalho.

\section{Considerações sobre a escrita do ponto de vista enunciativo}

Diante dos objetivos propostos neste artigo, por meio dos quais olhamos para a escrita na prova de redação do ENEM sob o ponto de vista enunciativo, cabe-nos pensar em como a teorização benvenistiana ${ }^{2}$ trata os conceitos de enunciação e enunciação escrita e em como podemos relacionar esses conceitos com o trabalho de escrita escolar.

Em O aparelho formal da enunciação, Benveniste propõe um quadro formal, que se desenha pelo processo de enunciação, e é marcado por uma relação discursiva entre os parceiros, o que configura a estrutura do diálogo, já que instaura duas figuras: "uma, origem, a outra, fim da enunciação" (BENVENISTE, 2006, p. 87). Essas duas figuras são constitutivas da enunciação, porém, não necessariamente, dividem o mesmo espaço e tempo, pois ao considerarmos que a categoria de tempo se renova a cada discurso produzido, o locutor, na enunciação, apropria-se da língua, ou seja, torna-a apta a um uso específico, e, assim, projeta um alocutário, que poderá produzir uma outra enunciação de retorno.

A partir desse ponto, o texto de Benveniste (2006) instaura uma discussão sobre a enunciação falada e a enunciação escrita. Para o autor,

muitos outros desdobramentos deveriam ser estudados no contexto da enunciação. Ter-se-ia que considerar as alterações lexicais que a enunciação determina, a fraseologia, que é a marca frequente, talvez necessária, da oralidade. Seria preciso também distinguir a enunciação falada da enunciação escrita. Esta se situa em dois planos: o que escreve se enuncia ao escrever e, no interior de sua escrita, ele faz os indivíduos se enunciarem. (BENVENISTE, 2006, p. 90)

Pela perspectiva com a qual Benveniste encerra o seu texto, entendemos que a existência da enunciação escrita, assim como a enunciação oral, pressupõe uma relação dialógica, uma vez que, ao se enunciar pela escrita, o locutor também implanta a possibilidade de uma enunciação de retorno, mesmo que o alocutário pretendido não esteja presente no momento de enunciação. Isso faz com que haja uma criação desejada e/ou imaginada de um leitor.

\footnotetext{
${ }^{2}$ A fundamentação teórica da pesquisa de doutorado da qual esse artigo é um recorte está calcada nos estudos que fazemos da obra de Emile Benveniste (1902-1976), sobretudo em relação aos conceitos elaborados ao longo dos "Problemas de Linguística Geral" (tomos I e II) e na teorização sobre escrita presente na obra "Últimas Aulas" (2014). Para este artigo, baseamo-nos, especialmente, na leitura que fazemos do texto "O aparelho formal da enunciação (1970)" bem como apresentamos alguns conceitos, presentes nas "Últimas aulas", que sustentam a nossa discussão.
}

Revista do SELL, Uberaba/MG (online) - V. 10 n. 1, p. 01-20, jan. /jun. - 2021. 
FERNANDES, L.A.M.L.; AGUSTINI, C.L.H.

Numa comparação entre enunciação falada e enunciação escrita, retornamos à descrição de Benveniste sobre o processo de referência na enunciação, caracterizada como "um pouco abstrata" (BENVENISTE, 2006, p. 84) e transferimos essa análise para a enunciação escrita. Nesse caso, a escrita, não mais relacionada com o som, mas com o grafo e a visão, torna-se imaterial/abstrata, o que permite que ela seja abordada como um lugar de enunciação com características próprias.

A enunciação suscita uma outra enunciação; é um processo de apropriação do aparelho formal da língua que faz com que o locutor enuncie sua posição e, ao mesmo tempo, implante um alocutário. (BENVENISTE, 2006, p. 84). Pelo viés enunciativo, na escrita, esse processo também é acirrado, já que é necessário o estabelecimento de uma relação enunciativa entre escritor e leitor. Nesse sentido, consideramos que a escrita implica também um processo de subjetividade e intersubjetividade, uma vez que na enunciação escrita aquele que se enuncia está ausente, mas, ao se subjetivar na e pela escrita, projeta um leitor, que no momento de leitura, constituirá uma nova enunciação, fazendo a escrita re-viver em sentido. Dessa forma, pensamos que, nas redações dissertativo-argumentativas do ENEM, o candidato/autor projeta um leitor para o seu texto, o leitor/avaliador da redação, e procura, a partir das orientações e estratégias trabalhadas nas aulas de Redação, atingir as expectativas desse leitor projetado em relação às instruções e ao tema propostos, de acordo com as competências a serem avaliadas.

Em Costa e Silva; Endruweit (2011, p. 236) lemos que "tratar de enunciação é entender que a língua é posta em funcionamento por um ato individual de utilização. É o uso que atualiza a língua”. Assim, enunciar implica ser capaz de se apropriar do aparelho formal da língua, reconhecendo que, na própria língua, existe um mecanismo que permite ao sujeito se colocar como "eu" e, com esse movimento, implantar o outro diante de si. No Aparelho, lemos que "o que em geral caracteriza a enunciação é a acentuação da relação discursiva com o parceiro". (BENVENISTE, 2006, p. 87). O termo "parceiro" merece destaque, pois evidencia que o que caracteriza o ato é a existência de um outro, que configura o discurso conosco, que permite que eu me instaure, um outro que se coloca no lugar de tu para que seu parceiro seja eu. Assim, se toda enunciação é uma locução e postula um alocutário, com a enunciação escrita não é diferente. A Enunciação escrita também é uma das formas complexas de discurso, um ato enunciativo, com características distintas da enunciação falada e que também implica uma relação de intersubjetividade.

Ainda na perspectiva de Benveniste (2014), a escrita é sempre a escrita de um sujeito e, por isso, a escrita projeta o sujeito que a (re)produz, de modo que o sujeito é o 
FERNANDES, L.A.M.L.; AGUSTINI, C.L.H.

próprio efeito que sua escrita produz no outro. Sendo assim, entendemos que a escrita bem antes de estar a serviço da forma, está a serviço de um escritor que coloca a língua em funcionamento para escrever. A escrita é assim, para Benveniste, um ato enunciativo que demanda do locutor a apropriação da língua escrita e seu manejo de forma que seja possível (entre) ver um traço de subjetividade em seu escrito e de forma que ele consiga enunciar, pela escrita, de sua posição, e produzir sentido. Assim compreendida, a escrita (pres)supõe o estabelecimento de uma configuração enunciativa, a fim de que a relação discursiva possa se efetivar. A escrita é endereçada a um alocutário virtual que é projetado no e pelo mo(vi)mento de escrita no processo que a constitui.

\section{Caracterização da redação escolar modelo ENEM}

O ENEM foi criado em 1998 com o objetivo de avaliar o desempenho do estudante ao final da Educação Básica e, assim, detectar lugares e instituições que precisariam de alguma intervenção a fim de homogeneizar o ensino no Brasil. Em 2004, 0 resultado do exame passou a ser utilizado como um dos critérios de seleção dos alunos que concorriam às bolsas do Programa Universidade para Todos - PROUNI. A partir de 2009, o exame passou a ser utilizado também como mecanismo para ingresso no ensino superior, seja combinado com os processos seletivos próprios das instituições ou como fase única de seleção, por meio do SISU - Sistema de Seleção Unificada ${ }^{3}$.

A prova do ENEM é constituída por questões de múltipla escolha, nas áreas Ciências Humanas e suas Tecnologias; Ciências da Natureza e suas Tecnologias; Linguagens, Códigos e suas Tecnologias; Matemática e suas Tecnologias, além da prova de redação, que recebe uma maior atenção dos candidatos, uma vez que a nota a ela atribuída tem um peso maior na média final do exame. A redação do ENEM exige do candidato/autor "a produção de um texto em prosa, do tipo dissertativo-argumentativo, sobre um tema de ordem social, científica, cultural ou política" (BRASIL, 2016, p. 7). Os aspectos a serem avaliados, segundo os documentos reguladores da prova, relacionamse às competências desenvolvidas durante os anos de escolaridade: 1) Demonstrar domínio da modalidade escrita formal da Língua Portuguesa; 2) Compreender a proposta de redação e aplicar conceitos das várias áreas de conhecimento para desenvolver o tema, dentro dos limites estruturais do texto dissertativo-argumentativo em prosa; 3 ) Selecionar, relacionar, organizar e interpretar informações, fatos, opiniões e argumentos em defesa de um ponto de vista; 4) Demonstrar conhecimento dos mecanismos

${ }^{3}$ Dados disponíveis em: http://inep.gov.br/enem/historico. Acesso em 10 Out. 2020.

Revista do SELL, Uberaba/MG (online) - V. 10 n. 1, p. 01-20, jan. /jun. - 2021. 
FERNANDES, L.A.M.L.; AGUSTINI, C.L.H.

linguísticos necessários para a construção da argumentação; 5) Elaborar proposta de intervenção para o problema abordado, respeitando os direitos humanos (BRASIL, 2016).

Todas essas determinações e orientações para escrita do texto dissertativoargumentativo na prova de redação do ENEM acabam por influenciar as aulas de Língua Portuguesa/Redação, especialmente, no terceiro ano do ensino médio, e o objetivo da disciplina passa a ser a preparação para a referida prova, já que a prova do ENEM se instaura como uma avaliação e seleção para o ensino superior. Dessa forma, o processo de escrita passa a ser baseado em técnicas e modelos que atendam às competências às quais serão avaliadas.

Segundo o documento "Redação do ENEM 2016 - Cartilha do Participante"4, a nota atribuída à redação do ENEM é calculada a partir da análise das cinco competências supracitadas, sendo, cada uma, avaliada em até 200 pontos. Ainda de acordo com o referido material, cada competência apresenta itens que devem ser obedecidos pelo candidato/autor para que seja obtida a nota máxima. Descrevemos a seguir alguns desses critérios.

Na competência 1, é avaliado, segundo a Cartilha "o domínio da modalidade escrita formal da Língua Portuguesa". Para isso, o candidato/autor deve procurar ser claro, objetivo, direto; empregar um vocabulário mais variado e preciso, diferente do que utiliza quando fala; e seguir as regras prescritas pela modalidade escrita formal da Língua Portuguesa. (BRASIL, 2016, p. 13, grifos nossos).

$\mathrm{Na}$ competência 2, a noção de argumentação está relacionada à estrutura clássica de texto dissertativo-argumentativo que consiste em introdução, desenvolvimento e conclusão, sendo a introdução apresentada como a parte do texto que apresenta a proposição, a tese a ser desenvolvida; o desenvolvimento consiste no desenrolar da ideia central apresentada, e a conclusão, parte final da produção escrita, na qual se reafirma o ponto de vista como decorrência da argumentação. Essa caracterização do processo de construção da argumentação envolve uma escrita que se limita ao uso de estratégias argumentativas capazes de expor o problema discutido no texto e detalhar os argumentos utilizados, sem fugir da estrutura previamente estabelecida. Ainda segundo a Cartilha do

\footnotetext{
${ }^{4}$ A caracterização da prova de redação do ENEM apresentada neste tópico está de acordo com o material "Redação do ENEM 2016": Cartilha do participante: Disponível em: http://download.inep.gov.br/educacao_basica/enem/guia_participante/2018/manual_de_redacao_do_enem 2016.pdf. A primeira versão dessa Cartilha foi disponibilizada aos candidatos em agosto de 2012 . Em 2013 , o INEP disponibiliza uma versão atualizada, que se mantém até 2016, quando é lançada uma nova Cartilha, com atualizações em 2017 e 2018. Desde a Cartilha de 2012, o objetivo do material é tornar o mais transparente possível a metodologia da correção da redação, bem como o que se espera do participante em cada uma das competências avaliadas. A cada ano, a Cartilha traz, como exemplos, redações Nota Mil dos anos anteriores, analisadas pela equipe de avaliadores. Em outubro de 2019, foi publicada a "A redação no ENEM 2019: Cartilha do Participante", também disponível no site do INEP.
}

Revista do SELL, Uberaba/MG (online) - V. 10 n. 1, p. 01-20, jan. /jun. - 2021. 
FERNANDES, L.A.M.L.; AGUSTINI, C.L.H.

Participante, para a avaliação dessa competência, o aluno deve "desenvolver o tema por meio de argumentação consistente, a partir de um repertório sociocultural produtivo, e apresentar excelente domínio do texto dissertativo-argumentativo" (BRASIL, 2016, p. 20, grifos nossos). Nesse sentido, a noção de argumentação está relacionada à noção de treino, a partir de uma escrita institucionalizada de um gênero específico.

Em relação à avaliação da competência 3, a Cartilha do Participante traz a seguinte orientação para o candidato/autor: "apresentar informações, fatos e opiniões relacionados ao tema proposto, de forma consistente e organizada, configurando autoria, em defesa de um ponto de vista" (BRASIL, 2016, p. 21, grifos nossos). Esses argumentos devem apoiarse em conhecimentos enciclopédicos, linguísticos e interacionais, bem como em convenções sociais, que vão ancorar os raciocínios que estiverem sendo elaborados.

$\mathrm{Na}$ Competência 4, é avaliada a organização dos argumentos, por meio do uso adequado dos mecanismos linguísticos necessários para a construção da argumentação. Nesse sentido, será necessário que o candidato/autor demonstre que "articula bem as partes do texto e apresenta repertório diversificado de recursos coesivos" (BRASIL, 2016, p. 24, grifos nossos).

Para atender à exigência da competência 5, a orientação para o candidato/autor é a de que "[...] a sua redação, além de apresentar uma tese sobre o tema, apoiada em argumentos consistentes, deve oferecer uma proposta de intervenção na vida social. [...] a proposta de intervenção precisa ser detalhada; deve conter, portanto, a exposição da intervenção sugerida e o detalhamento dos meios para realizá-la.” (BRASIL, 2016, p. 24, grifos nossos). Além disso, "é necessário respeitar os direitos humanos, não romper com valores como cidadania, liberdade, solidariedade e diversidade cultural." (BRASIL, 2016, p. 24, grifos nossos).

A partir dessa caracterização sobre os critérios avaliativos da produção textual cobrada no Exame, verificamos que é esperado do candidato/autor a produção de um texto no qual seja possível identificar o cumprimento das habilidades de escrita, instituídas, pelo exame, como imprescindíveis para a conclusão do ensino médio. Dessa forma, partindo do pressuposto de que isso seja possível, o exame solicita ao candidato/autor a escrita de um texto que será avaliado de acordo com os critérios preestabelecidos.

\section{A argumentação na prova de redação do ENEM}

A prova de redação do ENEM, embora anunciada pelos organizadores como inovadora, exige do candidato/autor a escrita de um texto com características e estrutura, previamente determinadas, o que reproduz o modelo clássico de "redação escolar". Ao 
FERNANDES, L.A.M.L.; AGUSTINI, C.L.H.

olharmos para a descrição dessa prova, sentimo-nos instigadas a pensar sobre o funcionamento da argumentação nessa produção textual escrita.

Nessa perspectiva, ao refletirmos sobre os critérios de avaliação desse texto no que se refere, especialmente, à construção da argumentação, pensamos que esta não se limita à sustentação de um ponto de vista por meio da seleção de argumentos e da construção de uma progressão temática que conduza o leitor/avaliador a julgar a tese defendida de modo adequado e fundamentado. A argumentação na prova de redação do ENEM está em função, primariamente, da avaliação da relação do candidato/autor com a língua escrita, com o repertório presente na proposta e com o manejo das formas de dizer "aceitas" socialmente. Assim, não está em jogo somente a posição defendida, mas o modo como essa posição é construída no e pelo texto e se essa posição está de acordo com o projeto de leitura estabelecido na e pela proposta de redação. Por isso, é necessário deslocarmos a argumentação de sua compreensão tradicional de defesa de um ponto de vista com a pretensão de convencer o outro (seu leitor) para a compreensão de seu funcionamento na prova de redação do ENEM.

É preciso, por conseguinte, pensar que, nessa prova, o candidato/autor deve se inscrever nos limites do regime enunciativo que rege a prova, a fim de que o texto produzido atenda à proposta. O conceito de regime enunciativo de que tratamos neste artigo e que orienta as nossas análises envolve o conjunto de coerções implícitas e explícitas que delineiam o processo de escrita na prova de redação do ENEM. Trata-se, segundo Agustini e Leite (2018) de uma configuração enunciativa que orienta o modo como a língua escrita deve acontecer, tanto em relação ao gênero textual quanto à situação de discurso. Diz respeito ainda ao modo como a escrita do candidato/autor organiza-se discursivamente, a partir do processo de identificação do candidato/autor com os saberes presentes na prova; proposta de redação.

Em decorrência desse deslocamento, pensamos que há um funcionamento específico da argumentação na prova de redação do ENEM e esse funcionamento nos traz algumas reflexões sobre a projeção de argumentação que essa prova traz; a definição de argumentação defendida e o modo como ela é construída a partir do regime enunciativo instaurado na proposta. De nossa perspectiva, a argumentação na redação do ENEM compreende, para além da defesa de um ponto de vista do candidato/autor, uma elaboração textual em função do regime enunciativo instituído na e pela proposta de redação da prova do ENEM. Essa argumentação está também relacionada à elaboração de um texto que faça um recorte temático, de modo a produzir um efeito de unidade, diante dos diferentes sentidos evocáveis nos e pelos textos motivadores. 
FERNANDES, L.A.M.L.; AGUSTINI, C.L.H.

\section{O regime enunciativo na prova de redação do ENEM:}

\section{análise da proposta de redação ENEM 2016}

A partir da noção que temos considerado sobre regime enunciativo, pensamos que a produção escrita da redação do ENEM envolve aspectos relacionados a coerções textuais e coerções discursivas. Mais especificamente em relação à argumentação, pensamos que argumentar refere-se à apropriação da língua escrita em função de tornála adequada à proposta e ao seu regime enunciativo.

Considerando a Cartilha do Participante, destacamos o que chamamos de coerções textuais, que dizem respeito às informações sobre o exame, de modo geral; sobre a prova de redação e, mais especificamente, sobre o texto a ser produzido, as competências que serão avaliadas e os critérios de correção e atribuição de notas. Estão presentes na cartilha também as razões para atribuição da nota zero e orientações sobre como não ferir os direitos humanos, inclusive apresentando exemplos de propostas que receberam nota zero em edições anteriores. Nesse sentido, verificamos que essas coerções estão explícitas na referida cartilha e, juntamente com outras informações trazidas também nas propostas de redação, como a quantidade de linhas e as razões para anulação, fazem parte do regime enunciativo da prova de redação do ENEM. Ainda em relação à proposta de redação, fica explícita também a frase temática, a partir da qual o candidato/autor deve desenvolver seu texto, as orientações para produção da redação e os textos motivadores, que devem orientar a reflexão e a escrita do texto, conforme 0 comando localizado no cabeçalho da proposta de redação.

Aquilo que chamamos de coerções discursivas, e que também fazem parte do regime enunciativo da prova de redação do ENEM, diz respeito às condições sociais e históricas que envolvem a produção escrita dessa redação, como o fato de esta fazer parte de um exame de avaliação e seleção de candidato para acesso ao ensino superior, de maior abrangência do país, o que faz dessa escrita uma escrita institucionalizada.

Diante dessas considerações, adotamos a perspectiva de que há condições enunciativas para que o candidato/autor elabore a sua redação no ENEM. Pensamos, ainda, que essas condições, ora aparecem explícitas, conforme já dissemos, na Cartilha do Participante, na proposta de redação e nas próprias condições de produção dessa escrita, ora configuram-se como coerções implícitas, instituídas na e pela proposta de redação, bem como pelas condições de produção em que essa prova é realizada. Outro aspecto relevante refere-se à relação entre o candidato/autor e o leitor/avaliador do exame. A projeção que o autor faz de seu leitor está, também, ligada ao regime enunciativo de produção escrita desse texto. Nesse sentido, a leitura que o 
FERNANDES, L.A.M.L.; AGUSTINI, C.L.H.

candidato/autor faz da proposta e a sua interpretação também serão preponderantes para a construção da argumentação.

Dessa forma, para a escrita desse texto, o candidato/autor precisa, dentre outros fatores, demonstrar domínio da língua escrita e esse "domínio" ou a falta dele se manifesta por meio do manejo que esse autor faz da língua escrita. Mais especificamente em relação à argumentação, pensamos que pode haver uma tensão entre o modelo de texto proposto na prova e o que, de fato, espera-se na escrita da redação. Ou seja, há uma tensão entre as coerções textuais e as coerções discursivas. Enquanto se espera uma defesa de um ponto de vista do candidato/autor no modelo clássico de redação dissertativo-argumentativa, discursivamente, na redação do ENEM, essa argumentação está relacionada a um regime enunciativo instituído na e pela proposta de redação.

Esse regime é também endossado pelos textos motivadores que culminam em uma orientação argumentativa, a qual "influencia" a construção da argumentação. Isso porque, mesmo quando orientados a apresentarem um repertório sociocultural, formado por argumentos externos aos textos motivadores, para embasar o ponto de vista defendido, o que ocorre é uma complementação de uma ideia já posta. Outro aspecto relevante diz respeito às informações que referenciam os argumentos e que, segundo os critérios de avaliação das competências, proporcionam uma melhor nota. Nesse caso, o que ocorre, muitas vezes, é a repetição de argumentos fundamentados nas mesmas referências, supostamente, escolhidas e apresentadas aos candidatos pelos professores em cursos preparatórios presenciais e em plataformas de ensino a distância.

Por meio das análises, estamos propondo, além das questões já apontadas, que, em consequência de uma escrita, cuja argumentação está pautada em um regime enunciativo instituído na e pela proposta de redação, os textos produzidos na prova de redação do ENEM são muito semelhantes, mesmo sendo produzidos por candidato/autores de diferentes cantos do país. Essa orientação argumentativa permite ainda que, mesmo em textos com notas muito distintas sejam identificados os "mesmos" pontos de vista e os "mesmos" argumentos. Sendo assim, é o manejo e a apropriação da língua escrita, que determinam tais notas, de acordo com critérios bem marcados e definidos para correção.

Considerando essas reflexões, intentamos mostrar como as coerções presentes na proposta de redação e nos textos motivadores organizam-se, de modo a já estabelecerem, a nosso ver, um regime enunciativo, que orientará a construção da argumentação na produção escrita da redação. Trazemos para esta análise, a proposta redação do ENEM 2016 e uma redação avaliada com nota mil no referido ano. 
FIGURA 01: Proposta de redação ENEM 2016.

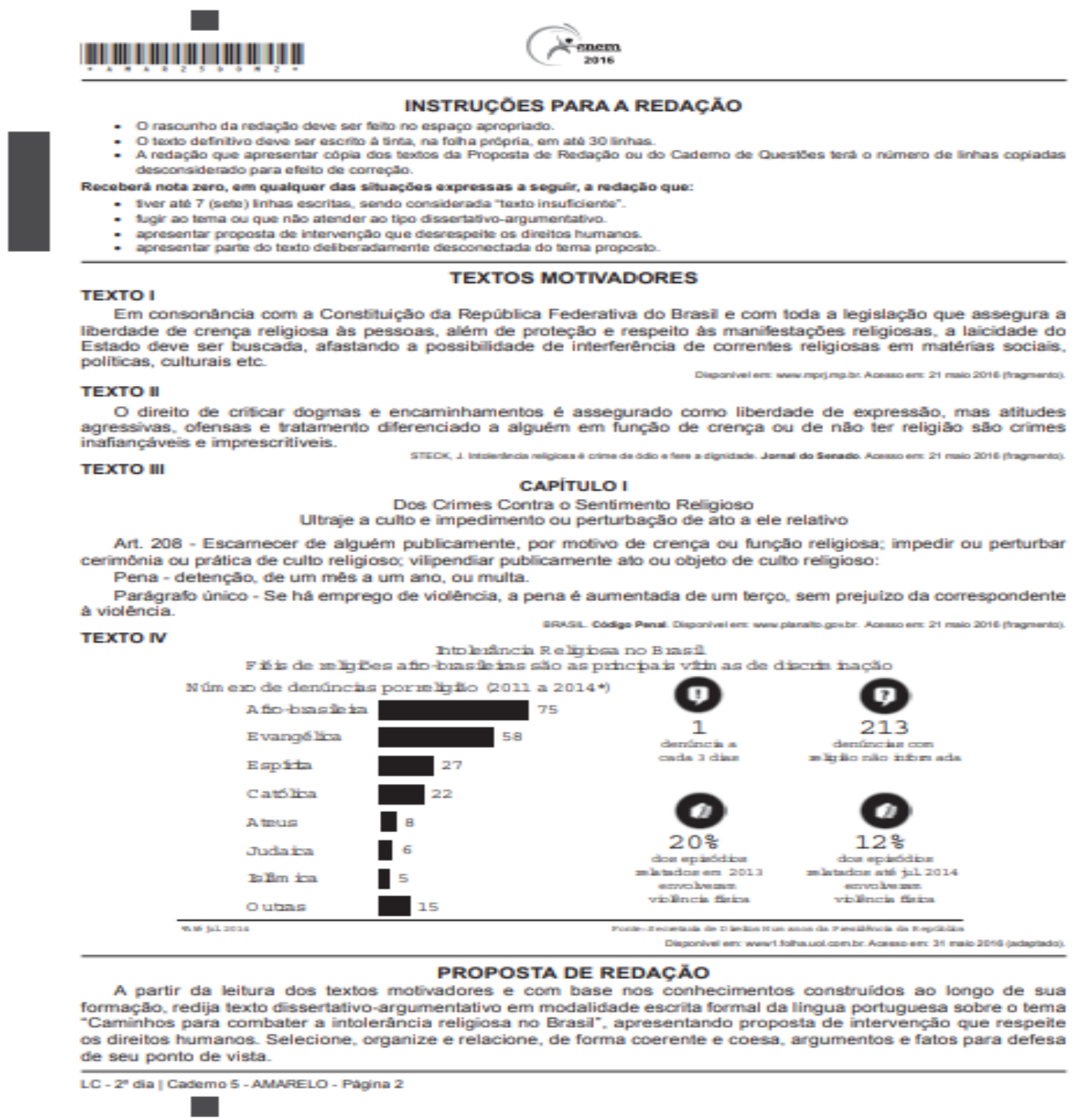

Fonte: Material compilado para o artigo. Disponível em: http://portal.inep.gov.br/provas-e-gabaritos

Em um primeiro momento, direcionamos a análise para o comando da prova pelo qual o candidato/autor é orientado a "redigir" um texto dissertativo-argumentativo, a partir da leitura dos textos motivadores e com base nos conhecimentos construídos ao longo da formação. Nesse caso, temos a impressão de uma orientação que permitiria ao candidato/autor, de certa forma, escrever sobre aquele tema, a partir do seu ponto de vista; orientação que vai ao encontro do que é didatizado na escola sobre o texto dissertativo-argumentativo e também é colocado no final do comando: "Selecione, organize e relacione, de forma coerente e coesa, argumentos e fatos para defesa de seu ponto de vista" (ENEM, 2016).

Revista do SELL, Uberaba/MG (online) - V. 10 n. 1, p. 01-20, jan. /jun. - 2021. 
FERNANDES, L.A.M.L.; AGUSTINI, C.L.H.

Tendo em vista esse quadro, já podemos nos perguntar: há, na própria proposta, arranjos linguísticos que direcionam a argumentação do candidato/autor? Como a frase temática e os textos motivadores atuam na construção do ponto de vista do candidato/autor?

Em relação à proposta de redação do ENEM 2016 (figura 01), considerando a frase temática "Caminhos para combater a intolerância religiosa no Brasil" destacamos que a orientação de que o candidato/autor deve escrever sobre os "caminhos" para combater a intolerância marca um ponto de vista, segundo o qual, existe a intolerância e ela precisa ser combatida. É necessário, assim, que o candidato/autor aponte "caminhos" para combatê-la. Não haveria, portanto, pela leitura da frase temática, a possibilidade de defender que não há esse tipo de intolerância no Brasil e de que ela não é recorrente. Em relação aos textos motivadores, as informações endossam essa afirmação: o texto I apresenta um trecho da Constituição Federal, que trata da liberdade de crença e da laicidade do Estado; o texto II explicita a diferença entre crítica e ofensa religiosa; o texto III expõe um trecho do Código Penal brasileiro, que tipifica o crime de intolerância religiosa e o texto IV apresenta um infográfico com os números de denúncias realizadas entre 2011 e 2014 por religião, o que ofereceu um panorama sobre a intolerância religiosa no Brasil.

Pela leitura dos textos motivadores e de toda a constituição linguístico-discursiva, bem como dos elementos não linguísticos presentes na prova de redação do ENEM 2016, consideramos que, pela proposta, é articulada uma perspectiva sobre um tema, endossada por textos compostos por diferentes formas de linguagem (textos motivadores), cuja compreensão pelo candidato/autor implicará na escrita de um texto com o mesmo ponto de vista. Destaca-se, também, na leitura desses textos, a informação de que todos foram publicados e/ou acessados recentemente, o que confirma a constância dos fatos. Isso mostra que os textos estão articulados de tal forma que o candidato/autor possa depreender deles o tema colocado e, assim, escrever o seu texto, ou seja, as escolhas do elaborador da proposta pelos elementos linguísticos (gramaticais, sintáticas e semânticas) e pelos textos motivadores (imagens, gráficos, trechos de reportagens, tabelas) produzem efeitos de sentido (verdades) sobre o tema.

Ainda no que se refere à influência dos textos motivadores na construção da argumentação na prova de redação do ENEM, consideramos importante analisar as orientações trazidas pela Cartilha do Participante sobre a leitura da proposta de redação e dos textos motivadores para que se obtenha uma boa nota. Vejamos algumas 
FERNANDES, L.A.M.L.; AGUSTINI, C.L.H.

recomendações que a cartilha traz sobre esses aspetos, cuja textualidade é marcada por verbos no modo imperativo, o que enfatiza a necessidade de atendimento a uma ordem:

Leia com atenção a proposta de redação e os textos motivadores, para compreender bem o que está sendo solicitado./ Evite ficar preso às ideias desenvolvidas nos textos motivadores, porque foram apresentadas apenas para despertar uma reflexão sobre o tema e não para limitar sua criatividade./Não copie trechos dos textos motivadores [...]./ Mantenha-se dentro dos limites do tema proposto, tomando cuidado para não se afastar de seu foco. (BRASIL, 2016, p. 15-16, grifos nossos).

Ao mesmo tempo em que se pede para não ficar preso às ideias dos textos e usar a criatividade, orienta-se que o candidato/autor mantenha-se dentro dos limites do tema proposto, o que mostra uma necessidade de um manejo da língua, de tal forma que ele permaneça na mesma direção argumentativa (im)posta pela proposta e pelos textos motivadores. Cumprindo ainda o papel de orientação ao candidato/autor, a versão da Cartilha, publicada em 2017, traz o que foi definido pela banca na avaliação da Competência 2, em relação à prova de 2016, considerando a leitura e compreensão da proposta e dos textos de apoio. Vejamos como foi construída essa orientação:

No Enem 2016, o tema se referia à discussão sobre formas para combater a intolerância religiosa no Brasil [...]. Com base no recorte definido pela proposta [...], o participante precisaria considerar as várias dimensões do problema contidas nos textos motivadores. A partir dessas informações, esperava-se que os textos produzidos se direcionassem para alguns contextos específicos: Contexto legal [...]; contexto de valorização cultural [...]; contexto de ações individuais [...]; contexto das ações de religiosos, discutindo a intolerância a grupos sociais e à liberdade individual de gênero e de sexualidade e a discriminação por raça, etnia e orientação política. (BRASIL, 2017, p, 16, grifos nossos).

Por essas orientações, vemos que há um limite na argumentação, já que o candidato/autor deve considerar apenas as dimensões do problema contidas nos textos motivadores e que os desdobramentos para as reflexões sobre o tema também já estão definidos tão logo a prova é elaborada. Nesse sentido, consideramos, mais uma vez, que, havendo esse parâmetro para correção, os pontos de vista já estão definidos. Assim, 0 que vai marcar a escrita nessa argumentação será o modo como o candidato/autor vai dar esse direcionamento a partir do manejo da língua escrita e do repertório mobilizado.

Sabemos que, por se tratar de uma avaliação de larga escala, na qual é necessária uma correção técnica, é inevitável o estabelecimento prévio de critérios para que seja possível uma avaliação justificável, porém, é justamente nessa necessidade que se encontra a nossa atenção. Há um funcionamento específico para a construção da argumentação nessa prova, que vai além dos limites do texto argumentativo- 
FERNANDES, L.A.M.L.; AGUSTINI, C.L.H.

argumentativo, e que considera as condições socioculturais e discursivas, a partir de um regime enunciativo implicado nesse processo de escrita.

\section{Análise de redação nota mil}

QUADRO 01: Redação nota 1000 (ENEM 2016)

\section{Tolerância na prática}

A Constituição Federal de 1988 - norma de maior hierarquia no sistema jurídico brasileiro - assegura a todos a liberdade de crença. Entretanto, os frequentes casos de intolerância religiosa mostram que os indivíduos ainda não experimentam esse direito na prática. Com efeito, um diálogo entre sociedade e Estado sobre os caminhos para combater a intolerância religiosa é medida que se impõe.

Em primeiro plano, é necessário que a sociedade não seja uma reprodução da casa colonial, como disserta Gilberto Freyre em "Casa-grande e Senzala". O autor ensina que a realidade do Brasil até o século XIX estava compactada no interior da casa-grande, cuja religião oficial era católica, e as demais crenças - sobretudo africanas - eram marginalizadas e se mantiveram vivas porque os negros Ihes deram aparência cristã, conhecida hoje por sincretismo religioso. No entanto, não é razoável que ainda haja uma religião que subjugue as outras, o que deve, pois, ser repudiado em um Estado laico, a fim de que se combata a intolerância de crença.

De outra parte, o sociólogo Zygmunt Bauman defende, na obra "Modernidade Líquida", que o individualismo é uma das principais características - e o maior conflito - da pós modernidade, e, consequentemente, parcela da população tende a ser incapaz de tolerar diferenças. Esse problema assume contornos específicos no Brasil, onde, apesar do multiculturalismo, há quem exija do outro a mesma postura religiosa e seja intolerante àqueles que dela divergem. Nesse sentido, um caminho possível para combater a rejeição à diversidade de crença é desconstruir o principal problema da pós-modernidade, segundo Zygmunt Bauman: o individualismo.

Urge, portanto, que indivíduos e instituições públicas cooperem para mitigar a intolerância religiosa. Cabe aos cidadãos repudiar a inferiorização das crenças e dos costumes presentes no território brasileiro, por meio de debates nas mídias sociais capazes de desconstruir a prevalência de uma religião sobre as demais. Ao Ministério Público, por sua vez, compete promover as ações judiciais pertinentes contra atitudes individualistas ofensivas à diversidade de crença. Assim, observada a ação conjunta entre população e poder público, alçará o país a verdadeira posição de Estado Democrático de Direito.

Fonte: Material compilado para o artigo. "Redação do ENEM 2017 - Cartilha do Participante"

A redação em análise recebeu nota mil (1000) no ENEM 2016, e é apresentada na Cartilha do Participante do ano seguinte, como um modelo, no qual o candidato/autor pode se espelhar para produzir o texto solicitado. Essa nota foi atribuída pela banca de avaliadores, que avaliou em 100\% (200 pontos) todos os critérios estipulados nas cinco competências analisadas na prova, conforme vista pedagógica 5 .

\footnotetext{
${ }^{5}$ As vistas pedagógicas são os espelhos de correção da prova de redação do ENEM, disponibilizados aos candidatos, por meio dos quais eles podem saber qual foi o resultado em cada uma das cinco competências avaliadas, seguindo os critérios pré-estabelecidos e comparar o desempenho com o dos demais candidatos daquela edição do exame.
}

Revista do SELL, Uberaba/MG (online) - V. 10 n. 1, p. 01-20, jan. /jun. - 2021. 
FERNANDES, L.A.M.L.; AGUSTINI, C.L.H.

Considerando o que já apresentamos sobre o regime enunciativo instaurado na e pela prova e a leitura que fazemos do texto em análise, vemos que ele é produzido com vistas a atender às demandas do exame, desde as orientações gerais sobre a estrutura textual até o recorte sobre a temática abordada. Nesse sentido, verificamos que a construção da argumentação está vinculada ao modo como o candidato/autor compreende o tema a partir da leitura que faz da frase temática, dos textos motivadores e das injunções que a prova lhe coloca.

Em relação à introdução do texto, apresentada no primeiro parágrafo (recorte 1), vê-se que o candidato faz um recorte da temática e a direciona para um campo já destacado nos textos motivadores.

A Constituição Federal de 1988 - norma de maior hierarquia no sistema jurídico brasileiro - assegura a todos a liberdade de crença. Entretanto, os frequentes casos de intolerância religiosa mostram que os indivíduos ainda não experimentam esse direito na prática. Com efeito, um diálogo entre sociedade e Estado sobre os caminhos para combater a intolerância religiosa é medida que se impõe (Recorte 1, grifos nossos).

Ao iniciar o texto com a citação da Constituição Federal, o candidato/autor traz para seu texto a referência apresentada pelo texto motivador I, bem como a discussão dos textos II e III, que exploram o campo legal em relação à temática da intolerância. Com esse recurso, a redação explora um dos contextos já esperados pela banca avaliadora e ainda atende ao que é avaliado na competência II, como mobilização de um repertório sociocultural. Além disso, o destaque dado aos "frequentes casos de intolerância religiosa" confirma a tese de que a intolerância existe, é frequente, atual e, por isso, precisa ser combatida, o que implica a necessidade de "caminhos", para esse combate, conforme assevera a frase temática, que orienta a produção textual escrita solicitada no exame.

Vemos nesse primeiro parágrafo que a redação se propõe a discutir o tema a partir do direcionamento presente na frase temática e na interpretação que o candidato/autor fez dos textos motivadores. Essa estratégia de introdução permite que a banca identifique, já no início da redação, esse alinhamento com a proposta apresentada. Instaura-se, assim, na enunciação escrita, uma relação discursiva em que o candidato/autor organiza seu texto, de tal maneira que atenda ao esperado pelo leitor/avaliador do texto, mediante os critérios que serão usados na avaliação.

Nessa mesma perspectiva, nos dois parágrafos de desenvolvimento, o atendimento aos critérios estipulados para a correção da redação, já detalhados, inclusive 
FERNANDES, L.A.M.L.; AGUSTINI, C.L.H.

na Cartilha do Participante (2016), é marcadamente identificado, por exemplo, pelo uso das referências a autores e obras cujas teorias têm grande respaldo. Vejamos:

Em primeiro plano, é necessário que a sociedade não seja uma
reprodução da casa colonial, como disserta Gilberto Freyre em "Casa-
grande e Senzala". O autor ensina que a realidade do Brasil até o século
XIX estava compactada no interior da casa-grande, cuja religião oficial era
católica, e as demais crenças - sobretudo africanas - eram marginalizadas
e se mantiveram vivas porque os negros Ihes deram aparência cristã,
conhecida hoje por sincretismo religioso. No entanto, não é razoável que
ainda haja uma religião que subjugue as outras, o que deve, pois, ser
repudiado em um Estado laico, a fim de que se combata a intolerância
de crença (Recorte 2 , grifos nossos).

De outra parte, o sociólogo Zygmunt Bauman defende, na obra "Modernidade Líquida", que o individualismo é uma das principais características - e o maior conflito - da pós modernidade, e, consequentemente, parcela da população tende a ser incapaz de tolerar diferenças. Esse problema assume contornos específicos no Brasil, onde, apesar do multiculturalismo, há quem exija do outro a mesma postura religiosa e seja intolerante àqueles que dela divergem. Nesse sentido, um caminho possível para combater a rejeição à diversidade de crença é desconstruir o principal problema da pós-modernidade, segundo Zygmunt Bauman: o individualismo (Recorte 3, grifos nossos).

Ao trazer as referências às obras de Gilberto Freire (segundo parágrafo) e Zygmunt Bauman (terceiro parágrafo) o texto atende ao que é cobrado na competência 3, a qual instrui o candidato a "selecionar, relacionar, organizar e interpretar informações, fatos, opiniões e argumentos em defesa de um ponto de vista" (BRASIL, 2016, p.20), e também ao que é estipulado na competência 2, que orienta os candidatos a "aplicar conceitos das várias áreas de conhecimento" (BRASIL, 2016, p. 8) e a usar estratégias de argumentação como "citações ou depoimentos de pessoas especializadas no assunto " (BRASIL, 2016, p. 19). É conveniente ressaltar que essas referências são tidas como importantes fundamentações teóricas a respeito de distintas situações e recortes temáticos. Isso permite que elas sejam usadas para a discussão de temas variados presente na prova de redação do ENEM.

Ainda nos parágrafos de desenvolvimento, destaca-se o uso dos elementos coesivos, avaliados na competência 4, a qual exige do candidato/autor "demonstrar conhecimento dos mecanismos linguísticos necessários para a construção da argumentação" (BRASIL, 2016, p. 22). Vemos que, para relacionar a argumentação à tese apresentada na introdução, em cumprimento também à competência 3, no que diz respeito à hierarquia e o desenvolvimento dos argumentos, o candidato/autor usa duas expressões com o objetivo de garantir a progressão temática do texto: "Em primeiro plano", iniciando o segundo parágrafo e "De outra parte" no terceiro parágrafo. Além 
FERNANDES, L.A.M.L.; AGUSTINI, C.L.H.

disso, o jogo semântico estabelecido pelo uso de conectivos como "no entanto", "cuja", "pois", "a fim de" (segundo parágrafo) e "esse", "onde", "nesse sentido" (terceiro parágrafo) garantem ao candidato/autor avaliação total nos critérios da competência 4, avaliada pela banca como bem articulada e com a presença de repertório diversificado de recursos. Essas ações em relação à escrita do texto mostram que o candidato/autor maneja a língua escrita de tal forma que seja possível estabelecer as relações semânticas necessárias à construção de sentido do texto e, ao mesmo tempo, atender ao que é esperado pela banca avaliadora.

Em relação ao último parágrafo do texto, chama-nos atenção o modo como a conclusão é elaborada a partir das orientações dos materiais de apoio ao candidato/autor disponibilizados pelo INEP. Assim, verifica-se a presença da proposta de intervenção, critério avaliado na competência 5 , bem como de todos os elementos estipulados pela banca como necessários para que essa proposta seja considerada completa, elaborada "de forma detalhada, relacionada ao tema e articulada à discussão desenvolvida no texto" (BRASIL, 2016, p. 25), conforme vemos no último parágrafo do texto.

Urge, portanto, que indivíduos e instituições públicas cooperem para mitigar a intolerância religiosa. Cabe aos cidadãos repudiar a inferiorização das crenças e dos costumes presentes no território brasileiro, por meio de debates nas mídias sociais capazes de desconstruir a prevalência de uma religião sobre as demais. Ao Ministério Público, por sua vez, compete promover as ações judiciais pertinentes contra atitudes individualistas ofensivas à diversidade de crença. Assim, observada a ação conjunta entre população e poder público, alçará o país a verdadeira posição de Estado Democrático de Direito (Recorte 4, grifos nossos).

$\mathrm{Na}$ elaboração desse parágrafo, são apresentadas algumas propostas que podem ser analisadas como "caminhos para combater a intolerância religiosa", conforme foi solicitado na frase temática e retomado pelo candidato na tese da redação. Dentre essas propostas, verifica-se a presença dos elementos solicitados pela grade de correção da prova em 2016, pela qual "a proposta de intervenção precisa ser detalhada; deve conter, portanto, a exposição da intervenção sugerida e o detalhamento dos meios para realizá-la" (BRASIL 2016, 24). Assim ao estabelecer, por exemplo, a ação/proposta (repudiar a inferiorização das crenças e dos costumes presentes no território brasileiro); o agente (cidadãos); o meio (por meio de debates nas mídias sociais) e o objetivo (mitigar a intolerância religiosa), o texto analisado atende aos critérios da competência 5. Nesse caso, mais uma vez, o uso dos elementos coesivos é fundamental para estabelecer os sentidos esperados pelo jogo estabelecido na proposta de intervenção, conforme solicitado pela banca.

Revista do SELL, Uberaba/MG (online) - V. 10 n. 1, p. 01-20, jan. /jun. - 2021. 
FERNANDES, L.A.M.L.; AGUSTINI, C.L.H.

Podemos pensar, assim, no caso da redação analisada, que se trata de um candidato/autor, cuja relação com a língua escrita ocorre de maneira sólida e isso permite que ele jogue com os recursos linguísticos de maneira a cumprir as determinações da banca avaliadora já estipuladas nos materiais que constituem as coerções textuais (im)postas pelo exame, inclusive na determinação da competência 1 que espera do candidato/autor: "demonstrar domínio da modalidade escrita formal da Língua Portuguesa" (BRASIL, 2016, p. 13). Dessa forma, a atribuição de 200 pontos (100\%) na correção de todas as competências mostra que, também pelo manejo da língua, 0 candidato/autor foi capaz de elaborar o seu texto de maneira que este pudesse ser avaliado positivamente a partir da grade de correção usada pela banca avaliadora. Esse efeito de encaixe é que, nos moldes de avaliação do ENEM, garante a nota mil.

Nessa perspectiva, o candidato/autor, interpelado na e pela prova de redação do ENEM e pelas coerções textuais e discursivas, consegue entrar no jogo interlocutivo instaurado pelo exame e atender a essa interpelação, em particular ao que tange o processo de argumentação, uma vez que o ponto de vista defendido no texto, pela análise que fazemos, já estava marcado no regime enunciativo da proposta.

\section{CONSIDERAÇÕES FINAIS}

Ao final deste artigo, considerando o objetivo do ENEM de selecionar candidatos aptos ao ensino superior e que demonstrem, mais especificamente, em relação à prova de redação, "as competências que devem ter sido desenvolvidas durante os anos de escolaridade" (BRASIL, 2016, p. 7), pensamos que esse candidato/autor, que tem seu texto avaliado com nota mil, consegue, por meio da sua produção textual escrita, atender a essa demanda. Em relação à construção da argumentação, vemos que a redação produzida se filia à orientação argumentativa presente no regime enunciativo da prova de redação que (im) põe um gesto de leitura específico em detrimento de outros possíveis. Já no que diz respeito às condições sociais do exame, verificamos também que o candidato/autor atende a uma coerção, diante de uma política de avaliação, colocada oficialmente como porta de acesso para uma pretensa "democratização" do ensino superior no país, mas que, de fato, funciona como uma política de seleção. 


\section{REFERÊNCIAS}

AGUSTINI, Cármen Lúcia Hernandes; LEITE, João de Deus. (2018). Dos relatos reflexivos do Estágio Supervisionado em Língua Portuguesa: a questão do regime enunciativo. In: Signum: Estudos da Linguagem, Londrina, v. 21, n. 3, p. 346-366, dez. 2018.

BENVENISTE, Émile. (1970). O aparelho formal da enunciação. In: BENVENISTE, Émile. Problemas de Linguística Geral II. 2.ed. Tradução de Eduardo Guimarães et.al. Campinas: Pontes Editores, 2006, p. 81-90

BENVENISTE, Émile. Últimas aulas no Collège de France (1968 e 1969). Tradução Daniel Costa da Silva et al Paris: 1.ed. São Paulo: Editora Unesp, 2014.

BRASIL. Ministério da Educação. INEP. Redação no ENEM 2016. Cartilha do Participante, Brasília, 2016.

BRASIL. Ministério da Educação. INEP. Redação no ENEM 2017. Cartilha do Participante, Brasília, 2017.

BRASIL. Ministério da Educação. Parâmetros Curriculares Nacionais (Ensino Médio) Linguagens, Códigos e suas Tecnologias. Brasília: Secretaria de Educação Média e Tecnológica, 2000. Disponível em: http://portal.mec.gov.br/seb/arquivos/pdf/14_24.pdf. Acesso em: 06 Set. 2019.

BRASIL. Ministério da Educação. PCN+ Ensino Médio: Orientações Educacionais Complementares aos Parâmetros Curriculares Nacionais - Linguagens, Códigos e suas tecnologias. Brasília: Secretaria de Educação Média e Tecnológica, s/d. Disponível em: http://portal.mec.gov.br/seb/arquivos/pdf/linguagens02.pdf. Acesso em: 06 Set. 2019.

COSTA E SILVA, Carmem Luci; ENDRUWEIT, Magali Lopes. O oral e o escrito sob o viés enunciativo: reflexões metodológicas. In: ReVEL, v. 9, n. 16, 2011. Disponível em: http://www.revel.inf.br/files/artigos/revel_16_o_oral_e_o_escrito_sob_o_vies_enunciativo. pdf. Acesso em: 25 Ago. 2020.

\section{Como citar este artigo (ABNT)}

FERNANDES, L.A.M.L.; AGUSTINI, C.L.H. O regime enunciativo na prova de redação do ENEM. Revista do SELL, Uberaba, MG, v. 10, n. 01, p. 01-20, 2021. Disponível em: <inserir link de acesso>. Acesso em: inserir dia, mês e ano de acesso. DOI: inserir link do DOI.

Como citar este artigo (APA)

Fernandes, L.A.M.L. \& Agustini, C.L.H. (2021). O regime enunciativo na prova de redação do ENEM. Revista do SELL, 10 (1), 01-20. DOI: inserir link completo de acesso ao DOI. 